Check for updates

Cite this: J. Mater. Chem. A, 2018, 6 , 11884

\section{Light-induced degradation of fullerenes in organic solar cells: a case study on TQ1:PC ${ }_{71} \mathrm{BM}^{\dagger}$}

\author{
Yuming Wang, ${ }^{\mathrm{ab}}$ Mohammad Javad Jafari, (D) ${ }^{\mathrm{b}}$ Nana Wang, ${ }^{a}$ Deping Qian, ${ }^{\mathrm{b}}$ \\ Fengling Zhang, ${ }^{\mathrm{b}}$ Thomas Ederth, (D) ${ }^{\mathrm{b}}$ Ellen Moons, (D) ${ }^{\mathrm{C}}$ Jianpu Wang, ${ }^{\text {a }}$ Olle Inganäs, ${ }^{\mathrm{b}}$ \\ Wei Huang ${ }^{a}$ and Feng Gao (DD *b
}

\begin{abstract}
The stability of organic solar cells (OSCs) is critical for practical applications of this emerging technology. Unfortunately, in spite of intensive investigations, the degradation mechanisms in OSCs have not been clearly understood yet. In this report, we employ a range of spectroscopic and transport measurements, coupled with drift-diffusion modelling, to investigate the light-induced degradation mechanisms of fullerene-based OSCs. We find that trap states formed in the fullerene phase under illumination play a critical role in the degradation of the open-circuit voltage $\left(V_{O C}\right)$ in OSCs. Our results indicate that the degradation is intrinsic to the fullerenes in OSCs and that alternative acceptor materials are desired for the development of stable OSCs.
\end{abstract}

Received 4th April 2018

Accepted 17th May 2018

DOI: $10.1039 / c 8 t a 03112 f$

rsc.li/materials-a

\section{Introduction}

Organic solar cells (OSCs) have attracted intensive attention during the past few decades. Very recently, the power conversion efficiency (PCE) of OSCs has reached a high value of above $14 \%,^{1,2}$ making this technology commercially relevant. However, the stability of OSCs remains an issue for the practical applications of OSCs.

The degradation of OSCs can be caused by different factors, including moisture, oxygen,$^{3-6}$ heat, ${ }^{7-10}$ and light. ${ }^{11-14}$ Among these different factors, to enhance the stability of OSCs under light is critically important for OSCs, as OSCs are inevitably illuminated during the operation. Light exposure can affect the photovoltaic parameters of OSCs in different ways. For instance, in some material systems mainly the short-circuit current $\left(J_{\mathrm{SC}}\right)$ and fill factor (FF) were affected by light exposure,,$^{15}$ while in some other systems mainly the open-circuit voltage $\left(V_{\mathrm{OC}}\right)$ was affected. ${ }^{16,17}$

Different mechanisms were found in light-induced degradation processes. For instance, new sub-band gap trap states were identified in polymer donor materials after exposure to light, and the light-induced new traps can broaden the density of states, decreasing the $V_{\mathrm{OC}}{ }^{16,17}$ In addition, the ultraviolet (UV) region of the spectrum can trigger the photochemical reaction

${ }^{a}$ Key Laboratory of Flexible Electronics (KLOFE), Institute of Advanced Materials (IAM), Nanjing Tech University (NanjingTech), 30 South Puzhu Road, Nanjing 211800, China. E-mail: iamjpwang@njtech.edu.cn

${ }^{b}$ Department of Physics, Chemistry and Biology (IFM), Linköping University, Linköping, SE-58183, Sweden. E-mail: feng.gao@liu.se

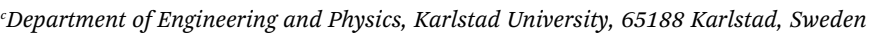
$\dagger$ Electronic supplementary information (ESI) available. See DOI: 10.1039/c8ta03112f between the polymer donor materials and the fullerene, resulting in irreversible degradation of the active layer. ${ }^{18}$ For fullerene based OSCs, the fullerene can be dimerized when exposed to light in an inert atmosphere. ${ }^{19-21}$ The dimerization of the fullerene could result in a significantly reduced carrier mobility or morphological changes of the active layer, leading to decreased $J_{\mathrm{SC}}$ and $\mathrm{FF} .{ }^{19-21}$

In this paper, we investigate the light-induced degradation mechanisms in a classical fullerene-based OSC blend solar cell, i.e. poly[2,3-bis-(3-octyloxyphenyl)quinoxaline-5,8-diyl-altthiophene-2,5-diyl] (TQ1):[6,6]-phenyl-C71-butyric acid methyl ester $\left(\mathrm{PC}_{71} \mathrm{BM}\right)$ (as shown in Fig. 1a). We find that the $V_{\mathrm{OC}}$ significantly decreases during the light-induced degradation process in both conventional and inverted device structures. We attribute the decrease of $V_{\mathrm{OC}}$ to non-radiative recombination, as identified by highly sensitive Fourier Transform Photocurrent Spectroscopy (FTPS), electroluminescence (EL) and external (a)

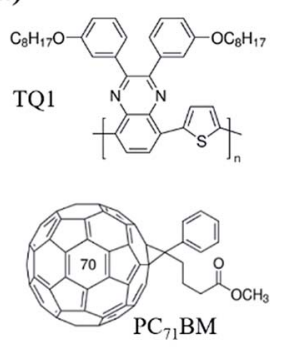

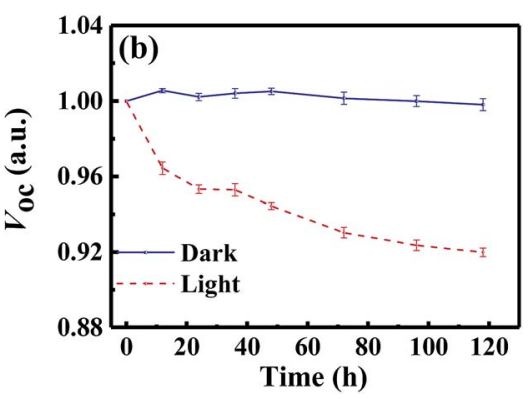

Fig. 1 (a) The chemical structures of TQ1 and PC $C_{71} B M$. (b) Evolution of normalized $V_{O C}$ of the devices with a conventional structure in the dark (solid line) and under illumination (dash line) as functions of time. 
quantum efficiency of EL $\left(\mathrm{EQE}_{\mathrm{EL}}\right)$ measurements. We combine temperature-dependent charge transport measurements and Extended Gaussian Disorder Modelling (EGDM) and find that the Gaussian disorder width of the electron states increases during the photo-degradation, while that of the holes remains the same. Fourier transform infrared spectroscopy (FTIR) measurements reveal that the fullerenes are oxidized during the degradation process, resulting in electron traps. These different measurements present a consistent picture that the photoinduced oxidation of fullerenes plays a critical role in the degradation of this system, resulting in electron traps and additional non-radiative recombination, which decreases the $V_{\text {OC }}$.

\section{Results and discussion}

We employ a conventional device structure, where the active layer is sandwiched between ITO/PEDOT:PSS and LiF/Al. As shown in Fig. $1 \mathrm{~b}$, the $V_{\mathrm{OC}}$ of the device stored under illumination (without load) shows a significant decrease, while the one of the device stored in the dark stays constant. The $V_{\mathrm{OC}}$ degradation can be due to either the interlayers or the active layer. ${ }^{22,23}$ In order to distinguish between the contribution from the interlayers and that from the active layer, we perform a control experiment on an inverted device, where the active layer is sandwiched between two different interlayers (ITO/ZnO and $\mathrm{MoO}_{x} / \mathrm{Al}$ ). Similar to that observed in the conventional structure, the $V_{\mathrm{OC}}$ in the inverted structure has also decreased upon light exposure for $72 \mathrm{~h}$ (Fig. S1d $\dagger$ ). In terms of the $J_{\mathrm{SC}}$ and FF, their degradation behaviour is obviously affected by the device structures (and hence the interlayers) (Fig. S1 and S2 $\dagger$ ), meaning that the effects of the interlayers and active layer cannot be easily separated in this case. ${ }^{23}$ The change in $V_{\mathrm{OC}}$, on the other hand, is the parameter that contains unique information about the light-induced degradation of the active layer, which is the focus of this work.

In order to understand the mechanisms of light-induced $V_{\mathrm{OC}}$ degradation, we quantify the $V_{\text {OC. }}$. In the bulk-heterojunction (BHJ) structured OSCs, the $V_{\mathrm{OC}}$ can be described using the following equations: ${ }^{24}$

$$
\begin{gathered}
V_{\mathrm{OC}}=E_{\mathrm{CT}}+\frac{k T}{q} \ln \left(\frac{J_{\mathrm{SC}} c h}{f q 2 \pi\left(E_{\mathrm{CT}}-\lambda\right)}\right)+\frac{k T}{q} \ln \left(\mathrm{EQE}_{\mathrm{EL}}\right), \\
\Delta V_{\mathrm{OC}}^{\mathrm{rad}}=\frac{k T}{q} \ln \left(\frac{J_{\mathrm{SC}} c h}{f q 2 \pi\left(E_{\mathrm{CT}}-\lambda\right)}\right)
\end{gathered}
$$

and

$$
\Delta V_{\mathrm{OC}}^{\mathrm{non}-\mathrm{rad}}=\frac{k T}{q} \ln \left(\mathrm{EQE}_{\mathrm{EL}}\right) .
$$

where $E_{\mathrm{CT}}$ is the energy of charge-transfer (CT) states, $k$ is Boltzmann's constant, $T$ is the absolute temperature, $\lambda$ is the reorganization energy related to the CT absorption process, $q$ is the elementary charge, $c$ is the speed of light in vacuum, $h$ is Planck's constant and $f$ is a prefactor. As shown in eqn (1), the $V_{\mathrm{OC}}$ consists of three components, including the energy of CT states, radiative recombination energy loss and non-radiative recombination energy loss. The first two parts can be determined by fitting the $\mathrm{EQE}_{\mathrm{PV}}$ or EL spectrum in the CT state regime and the last part correlates to the external efficiency of the EL $\left(\mathrm{EQE}_{\mathrm{EL}}\right)$ of the device. ${ }^{24,25}$

We investigate all three items in eqn (1) to determine the origin of the $V_{\mathrm{OC}}$ degradation under illumination. The absorption of the CT states is very weak because of the weak overlap between the highest occupied molecular orbital (HOMO) of the donor and the lowest unoccupied molecular orbital (LUMO) of the acceptor. Herein we employ a sensitive photocurrent spectroscopy method FTPS to measure the $\mathrm{EQE}_{\mathrm{PV}}$ in the CT state region. As shown in Fig. 2a, there is a region with a swollen FTPS signal at low energy, corresponding to the photocurrent due to CT state absorption. ${ }^{24-26}$ The shape of the $\mathrm{EQE}_{\mathrm{PV}}$ curve in the CT state region shows no change after $72 \mathrm{~h}$ illumination, indicating that there is no change in either the $E_{\mathrm{CT}}$ or $\Delta V_{\mathrm{OC}}^{\mathrm{rad}}$. In order to further confirm the information we obtained from the FTPS measurements, we measure the EL spectrum of the devices as well. As shown in Fig. 2b, the EL spectra of CT states (Fig. S3†) show no changes after $72 \mathrm{~h}$ illumination, consistent with the FTPS results.

The $\mathrm{EQE}_{\mathrm{EL}}$ results are depicted in Fig. 2c. Compared with the device stored in the dark, the $\mathrm{EQE}_{\mathrm{EL}}$ of the device aged under light decreases by one order of magnitude, corresponding to an increase of a non-radiative $V_{\text {OC }}$ loss by $\sim 60 \mathrm{meV}$ according to eqn (3). This result matches well with the overall $V_{\mathrm{OC}}$ decrease after $72 \mathrm{~h}$ illumination (Table $\mathrm{S} 2 \dagger$ ). We also perform $\mathrm{EQE}_{\mathrm{EL}}$ measurements on the inverted devices and obtain similar results (Fig. S4 and Table S4†), further confirming that the degradation originates from the active layer, rather than the interlayers. From this quantification of the light-induced $V_{\text {OC }}$ losses, we can conclude that the light-induced $V_{\text {OC }}$ loss stems from the increased non-radiative recombination losses in the active layer.

A possible reason for the increased non-radiative $V_{\mathrm{OC}}$ losses is the formation of additional trap states induced by illumination, leading to trap-assisted non-radiative recombination. A direct approach to investigate the traps is to perform temperature-dependent mobility measurements. ${ }^{27-29}$ Therefore, we measure the $J-V$ curves of the hole-only (HO) and electrononly (EO) devices based on blends at different temperatures. As shown in Fig. 3a, the electron transport of the blend devices decreases after $72 \mathrm{~h}$ illumination, meaning that degradation generates an increasing amount of electron traps. We can further quantify the disorder values in the devices before and after degradation by using EGDM. The details of this method are shown in the ESI of ref. 12. We find that the disorder value, which is denoted as $\sigma$, increases from $46 \mathrm{meV}$ to $50 \mathrm{meV}$ upon degradation (Fig. 3e and f). Surprisingly, the hole transport shows an enhancement after $72 \mathrm{~h}$ of illumination (Fig. 3d), the reason of which will be discussed later on.

In order to further confirm the light-induced electron traps and understand the unusual enhancement of the hole transport, we measure the single-carrier devices of the pristine materials (Fig. 3e and f). Indeed, consistent with the EO device of the blend, the EO device of $\mathrm{PC}_{71} \mathrm{BM}$ shows decreased transport, confirming light-induced electron traps. In contrast to the enhancement of the hole transport in the blend, the hole 

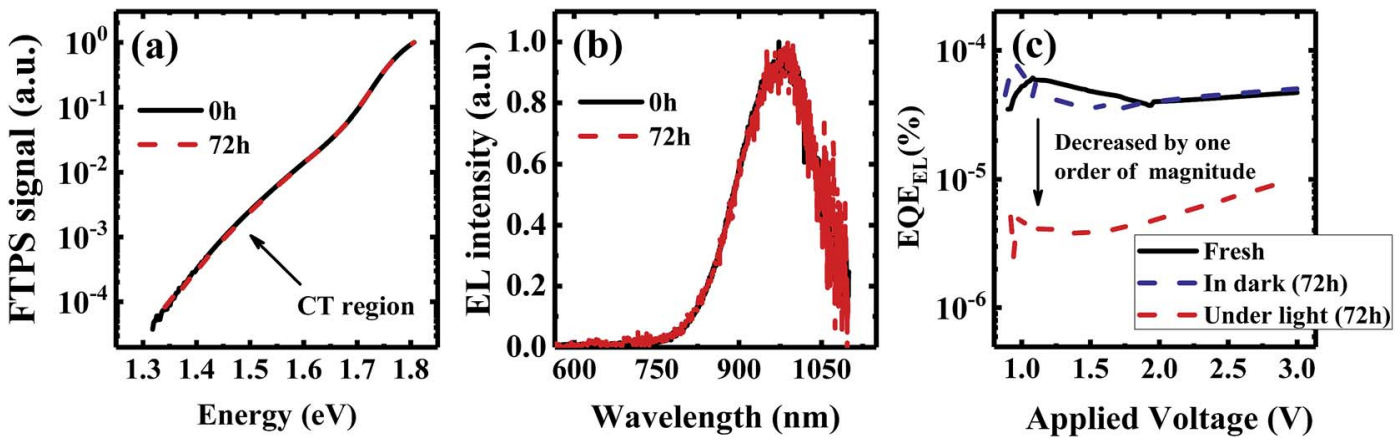

Fig. 2 (a) FTPS and (b) EL spectra of the fresh devices (black solid lines) and aged devices after $72 \mathrm{~h}$ illumination (red dashed lines). Both of the FTPS and EL spectra of CT states remain unchanged after illumination, indicating that there is no change in $E_{\mathrm{CT}}$ and $\Delta V_{\mathrm{OC}}^{\text {rad }}$. (c) $V$ ariation of $E Q E_{\mathrm{EL}}$ curves versus voltage. $\mathrm{EQE}_{\mathrm{EL}}$ of fresh devices (black and red solid lines), device aged in dark (blue dash line) and device aged under light (red dash line). All measurements are based on the conventional structure.

transport in the pristine TQ1 device shows no difference after $72 \mathrm{~h}$ illumination.

We further investigate the degradation processes at the molecular level with polarization-modulation infrared reflection-absorption spectroscopy (PM-IRRAS). As shown in Fig. $4 \mathrm{a}$, a new band appears at $\sim 1776 \mathrm{~cm}^{-1}$, near the $\mathrm{PC}_{71} \mathrm{BM}$ methyl ester carbonyl peak at $1732 \mathrm{~cm}^{-1}$, during the illumination in the TQ1:PC $\mathrm{PC}_{71} \mathrm{BM}$ blend film. $\mathrm{A}$ similar band at $\sim 1776 \mathrm{~cm}^{-1}$ also appears in the pure $\mathrm{PC}_{71} \mathrm{BM}$ film (Fig. $4 \mathrm{~b}$ ), but not in the pure TQ1 film (Fig. 4c), indicating that the new vibrational peak is due to the oxidation of $\mathrm{PC}_{71} \mathrm{BM}$. The fact that pure TQ1 shows no light-induced vibrational band is consistent with the charge transport result in Fig. 3f, where no change of the hole transport is observed in the HO device of TQ1. We propose that the formation of the band at $\sim 1776 \mathrm{~cm}^{-1}$ is due to the oxidation of carbon elements resulting in the formation of carbonyl groups $(\mathrm{C}=\mathrm{O})$ in $\mathrm{PC}_{71} \mathrm{BM}$. The origin of oxygen could be from the oxygen in the glovebox (5-10 ppm oxygen level) and/ or small amounts of oxygen remaining in the materials before they are transferred into the glovebox (the solid materials are stored outside in a fridge). It is now becoming clear why we observe abnormal enhancement of the hole transport in the blend film, as shown in Fig. 3d. We suppose that in the blend film, the oxygen in TQ1 tends to react with the $\mathrm{PC}_{71} \mathrm{BM}$ due to the scavenger properties of fullerene, ${ }^{30,31}$ helping to de-dope the polymer and thus improving the hole transport. ${ }^{32,33}$ This process was previously demonstrated to be facilitated by illumination..$^{20}$

In order to further demonstrate the oxidization of the materials, we intentionally expose the films in air under light
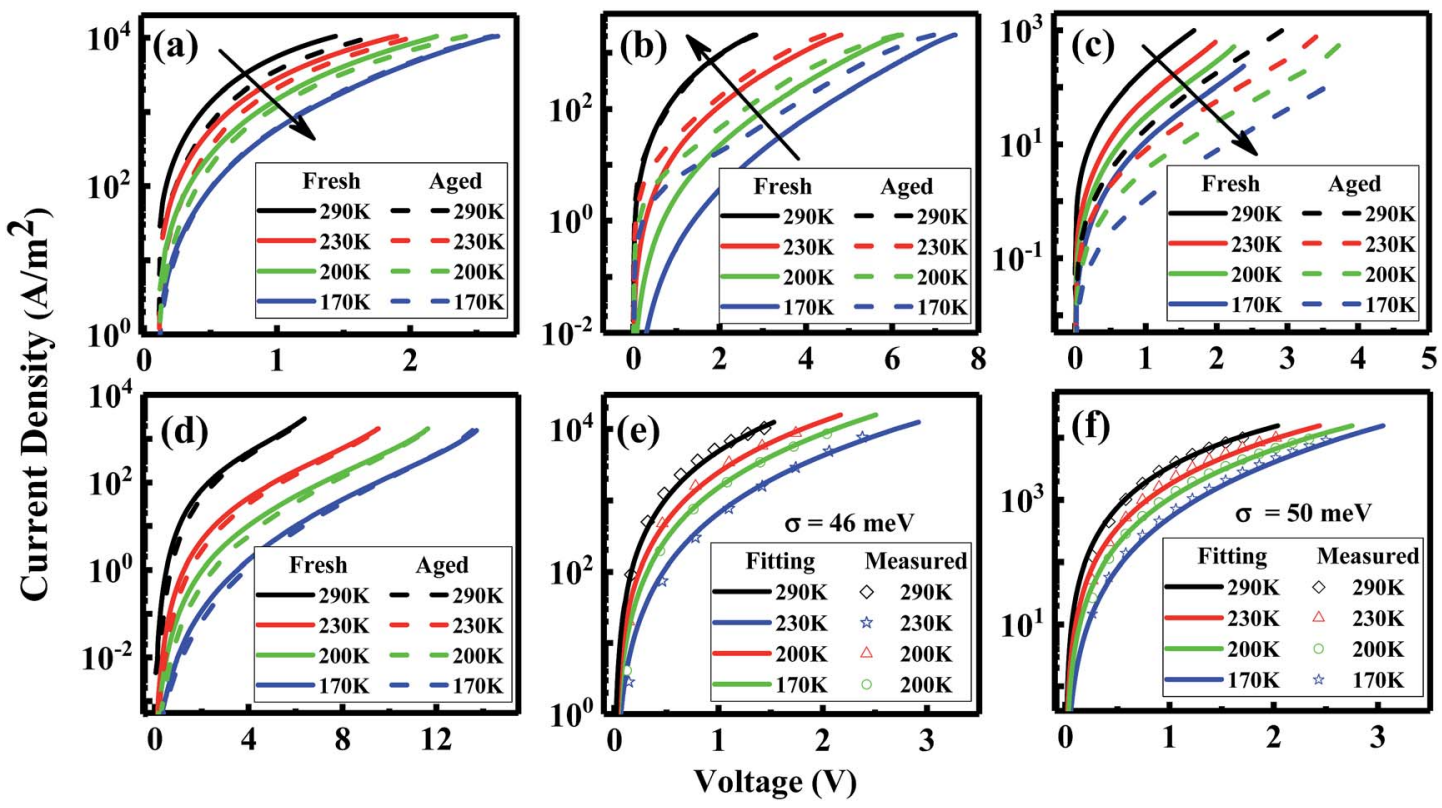

Fig. 3 Comparison of the temperature dependent $J-V$ curves of fresh and $72 \mathrm{~h}$ illumination aged devices are presented in (a-d), respectively. (a) Electron-only (EO) device based on blends, (b) hole-only $(\mathrm{HO})$ device based on blends, (c) $E O$ device based on pure $\mathrm{PC}_{71} \mathrm{BM}$, and (d) $\mathrm{HO}$ device based on pure TQ1. The fitting results of EO devices based on TQ1:PC ${ }_{71} B M$ are shown in (e) before and (f) after $72 \mathrm{~h}$ illumination. 

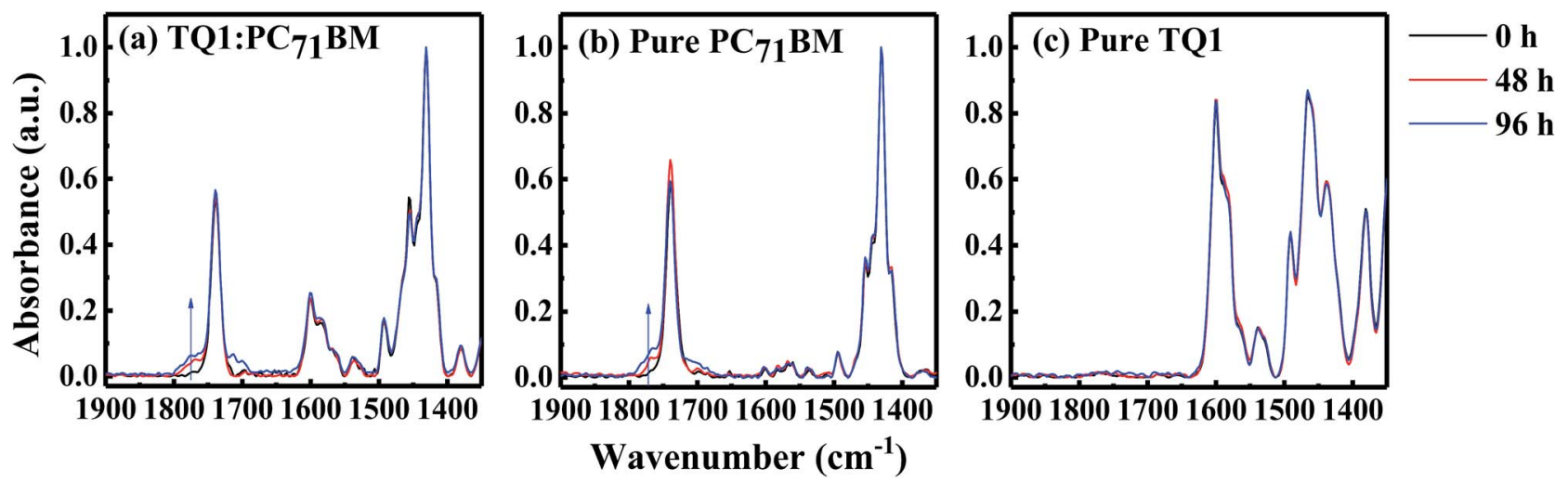

Fig. 4 FTIR measurements of the films based on (a) TQ1:PC 71 BM (1: 2.5); (b) pure PC ${ }_{71} B M$; (c) pure TQ1; all the films are stored in the glovebox when exposed to light; blue arrows indicate carbonyl bands emerging due to oxidation.

exposure, and then perform the FTIR measurements. As shown in Fig. S5a-c, $\dagger$ we observe that all the films exposed to air show a new vibration signal, corresponding to the carbonyl group. This vibration signal now emerges much more quickly, compared with the experiments performed in the glovebox, as a result of the large amounts of oxygen available in air. We notice that TQ1 in this case also shows an oxidation signal. The lack of the oxidation signal of the TQ1 film in the glove-box might be due to the fact that compared with $\mathrm{PC}_{71} \mathrm{BM}$, the TQ1 is less reactive with oxygen. ${ }^{34}$ Based on these results, we conclude that the newly appearing carbonyl vibrational band in Fig. 4a comes from the oxidation of $\mathrm{PC}_{71} \mathrm{BM}$ during the illumination.

\section{Conclusion}

We investigate the light-induced degradation of the devices based on TQ1: $\mathrm{PC}_{71} \mathrm{BM}$ and find that the oxidation of $\mathrm{PC}_{71} \mathrm{BM}$ (as revealed by FTIR results) plays a key role in the degradation of the device parameters, especially the $V_{\mathrm{OC}}$. The oxidation of $\mathrm{PC}_{71} \mathrm{BM}$ results in electron traps, leading to enhanced nonradiative recombination loss of the $V_{\mathrm{OC}}$, which we have quantified by measuring the electroluminescence quantum efficiency of the devices. We also quantified the energetic disorder induced by the electron trap states due to the oxidation of $\mathrm{PC}_{71} \mathrm{BM}$. Our work indicates that fullerene acceptors are detrimental to the light stability of devices, and alternative acceptor materials are required to develop stable OSCs. Our conclusion is in line with the recent trend towards the development of OSCs based on non-fullerene acceptors. ${ }^{3-38}$

\section{Experimental section}

\section{Solution preparation}

TQ1 is provided by Ergang Wang's group at Chalmers University of Technology and $\mathrm{PC}_{71} \mathrm{BM}$ is purchased from Solenne b.v. The polymer and fullerene mixtures are dissolved at a $1: 2.5 \mathrm{w} / \mathrm{w}$ ratio in 1,2-dichlorobenzene ( $o$-DCB). The total concentration of the TQ1:PC $\mathrm{PC}_{71} \mathrm{BM}$ blend in $o$-DCB is $25 \mathrm{mg} \mathrm{ml}^{-1}$. The TQ1 is dissolved in $o$-DCB with a concentration of $15 \mathrm{mg} \mathrm{ml}^{-1}$ and the
$\mathrm{PC}_{71} \mathrm{BM}$ is dissolved in chloroform (CF) with a concentration of $15 \mathrm{mg} \mathrm{ml}^{-1}$. All the solutions are stirred overnight at $60{ }^{\circ} \mathrm{C}$ before use. PEDOT:PSS Al 4083 is purchased from Heraeus and zinc oxide $(\mathrm{ZnO})$ nanoparticle solution is purchased from Suprapur.

\section{Device preparation}

All the solar cells are fabricated on an indium tin oxide (ITO) coated glass substrate and a $90 \mathrm{~nm}$ aluminium layer is used as the top contact. The ITO glass is cleaned in the TL1 process (boiled for $20 \mathrm{~min}$ in the mixed solution of hydrogen peroxide $\left(\mathrm{H}_{2} \mathrm{O}_{2}\right)$ and ammonia $\left.\left(\mathrm{NH}_{3}\right)\right)$. A structure of ITO/PEDOT:PSS/ active layer/LiF/Al is employed for the conventional structure device and a structure of $\mathrm{ITO} / \mathrm{ZnO} /$ active layer $/ \mathrm{MoO}_{x} / \mathrm{Al}$ is employed for the inverted structure device. A structure of ITO/ PEDOT:PSS/active layer $/ \mathrm{MoO}_{x} / \mathrm{Al}$ is employed for the HO devices and a structure of $\mathrm{ITO} / \mathrm{ZnO} /$ active layer/LiF/Al is employed for the EO devices. The thickness of the TQ1:PC ${ }_{71} \mathrm{BM}$ blend active layer is $\sim 90 \mathrm{~nm}$. The thickness of the pure TQ1 and $\mathrm{PC}_{71} \mathrm{BM}$ active layers is $\sim 80 \mathrm{~nm}$ and $\sim 110 \mathrm{~nm}$, respectively.

\section{Stability measurements}

All the devices studied in our experiments are encapsulated with a coverslip which is UV-glued on the surface of the device. The devices in the glovebox (filled with nitrogen, $\leq 1 \% \mathrm{ppm}$ moisture and $5-10 \%$ ppm oxygen) are divided into two groups, with one group stored in the dark and the other group stored under the illumination of a white LED. The LED spectrum is shown in Fig. S6 $\dagger$ and the intensity is calibrated to be $\sim 50 \mathrm{~mW}$ $\mathrm{cm}^{-2}$ with a standard Si solar cell. $J-V$ measurements of the devices are performed outside the glovebox. An AM1.5G sun simulator purchased from Oriel is used for the $J-V$ measurements.

\section{FTPS measurements}

FTPS measurements are performed on a Vertex 70 from Bruker optics, equipped with a QTH lamp, quartz beam-splitter and external detector option. A low noise current amplifier (SR570) is used to amplify the photocurrent produced by the 
illumination of FTIR on the devices. The output voltage of the amplifier is fed back to the external port of the FTIR, in order to be able to employ the FTIR software to collect the photocurrent spectrum.

\section{EL measurements}

A Keithley 2400 is used for supplying voltage/current to the devices. An Andor spectrometer (Shamrock sr-303i-B, coupled to a Newton EMCCD detector) is used to record the EL spectra.

\section{$\mathrm{EQE}_{\mathrm{EL}}$ measurements}

The $\mathrm{EQE}_{\mathrm{EL}}$ measurements are performed on a home built setup comprising a Hamamatsu silicon photodiode 1010B, a Keithley 2400 for supplying voltages and recording the injected current, and a Keithley 485 for measuring the emitted light intensity.

\section{FTIR measurements}

Polarization-modulation infrared reflection-absorption spectroscopy (PM-IRRAS) measurements are carried out by means of a Bruker PMA 50 with a LN2-cooled mercury cadmium telluride (MCT) detector at $86^{\circ}$ grazing angle, using a Bruker VERTEX70 as a light source. A photo-elastic modulator (Hinds: ZnSe 50 $\mathrm{kHz}$ ) is used to modulate the polarization of light. Spectra containing $\mathrm{PC}_{71} \mathrm{BM}$ are normalized to the fullerene peak near $1430 \mathrm{~cm}^{-1}$, and the TQ1 spectra normalized to the ring vibration at $1465 \mathrm{~cm}^{-1}$.

\section{Conflicts of interest}

There are no conflicts to declare.

\section{Acknowledgements}

The authors thank Dr Jonas Bergqvist for the supply of the LED. The authors are grateful to the National Basic Research Program of China (Grant No. 2015CB932200), Natural Science Foundation of Jiangsu (Grant No. BK20140952, BK20150043), National Natural Science Foundation of China (Grant No. 11474164, 61405091, 61634001), Joint Research Program between China and European Union (Grant No. 2016YFE0112000), Synergetic Innovation Center for Organic Electronics and Information Displays, National High Technology Research and Development Program of China (Grant No. 2011AA050520), Jiangsu SpeciallyAppointed Professor program, Chinese Scholarship Council (CSC), Swedish Research Council (VR), European Commission SOLAR-ERA-NET, Swedish Energy Agency (Energimyndigheten), Swedish Government Strategic Research Area in Materials Science on Functional Materials at Linköping University (Faculty Grant No. SFO-Mat-LiU \#2009-00971), and Knut and Alice Wallenberg foundation (KAW) for financial support.

\section{Notes and references}

1 Z. Xiao, X. Jia and L. Ding, Sci. Bull., 2017, 62, 1562.

2 S. Zhang, Y. Qin, J. Zhu and J. Hou, Adv. Mater., 2018, DOI: 10.1002/adma.201800868.
3 M. P. Nikiforov, J. Strzalka and S. B. Darling, Sol. Energy Mater. Sol. Cells, 2013, 110, 36.

4 Q. Bao, X. Liu, S. Braun and M. Fahlman, Adv. Energy Mater., 2014, 4, 1301272.

5 Y. W. Soon, H. Cho, J. Low, H. Bronstein, I. McCulloch and J. R. Durrant, Chem. Commun., 2013, 49, 1291.

6 S. Karuthedath, T. Sauermann, H.-J. Egelhaaf, R. Wannemacher, C. J. Brabec and L. Lüer, J. Mater. Chem. A, 2015, 3, 3399.

7 E. Vitoratos, S. Sakkopoulos, E. Dalas, N. Paliatsas, D. Karageorgopoulos, F. Petraki, S. Kennou and S. Choulis, Org. Electron., 2009, 10, 61.

8 T. Sachs-Quintana, T. Heumüller, W. R. Mateker, D. E. Orozco, R. Cheacharoen, S. Sweetnam, C. J. Brabec and M. D. McGehee, Adv. Funct. Mater., 2014, 24, 3978.

9 Z. Yi, W. Ni, Q. Zhang, M. Li, B. Kan, X. Wan and Y. Chen, J. Mater. Chem. C, 2014, 2, 7247.

10 Z. Li, H. C. Wong, Z. Huang, H. Zhong, C. H. Tan, W. C. Tsoi, J. S. Kim, J. R. Durrant and J. T. Cabral, Nat. Commun., 2013, 4, 2227.

11 E. A. Lukina, M. N. Uvarov and L. V. Kulik, J. Phys. Chem. C, 2014, 118, 18307.

12 M. O. Reese, A. M. Nardes, B. L. Rupert, R. E. Larsen, D. C. Olson, M. T. Lloyd, S. E. Shaheen, D. S. Ginley, G. Rumbles and N. Kopidakis, Adv. Funct. Mater., 2010, 20, 3476.

13 T. Tromholt, M. V. Madsen, J. E. Carlé, M. Helgesen and F. C. Krebs, J. Mater. Chem., 2012, 22, 7592.

14 H. K. H. Lee, A. M. Telford, J. A. Röhr, M. F. Wyatt, B. Rice, J. Wu, A. de Castro Maciel, S. M. Tuladhar, E. Speller, J. McGettrick, J. R. Searle, S. Pont, T. Watson, T. Kirchartz, J. R. Durrant, W. C. Tsoi, J. Nelson and Z. Li, Energy Environ. Sci., 2018, 11, 417.

15 C. J. Schaffer, C. M. Palumbiny, M. A. Niedermeier, C. Jendrzejewski, G. Santoro, S. V. Roth and P. MullerBuschbaum, Adv. Mater., 2013, 25, 6760.

16 T. Heumueller, T. M. Burke, W. R. Mateker, I. T. SachsQuintana, K. Vandewal, C. J. Brabec and M. D. McGehee, Adv. Energy Mater., 2015, 5, 1500111.

17 T. Heumueller, W. R. Mateker, I. T. Sachs-Quintana, K. Vandewal, J. A. Bartelt, T. M. Burke, T. Ameri, C. J. Brabec and M. D. McGehee, Energy Environ. Sci., 2014, 7, 2974.

18 D. Bartesaghi, G. Ye, R. C. Chiechi and L. J. A. Koster, Adv. Energy Mater., 2016, 6, 1502338.

19 N. Wang, X. Tong, Q. Burlingame, J. Yu and S. R. Forrest, Sol. Energy Mater. Sol. Cells, 2014, 125, 170.

20 T. Heumueller, W. R. Mateker, A. Distler, U. F. Fritze, R. Cheacharoen, W. H. Nguyen, M. Biele, M. Salvador, M. von Delius, H.-J. Egelhaaf, M. D. McGehee and C. J. Brabec, Energy Environ. Sci., 2016, 9, 247.

21 F. Piersimoni, G. Degutis, S. Bertho, K. Vandewal, D. Spoltore, T. Vangerven, J. Drijkoningen, M. K. Van Bael, A. Hardy, J. D'Haen, W. Maes, D. Vanderzande, M. Nesladek and J. Manca, J. Polym. Sci., Part B: Polym. Phys., 2013, 51, 1209.

22 Y.-M. Chang and C.-Y. Leu, J. Mater. Chem. A, 2013, 1, 6446. 
23 C. H. Peters, I. T. Sachs-Quintana, W. R. Mateker, T. Heumueller, J. Rivnay, R. Noriega, Z. M. Beiley, E. T. Hoke, A. Salleo and M. D. McGehee, Adv. Mater., 2012, 24, 663.

24 K. Vandewal, K. Tvingstedt, A. Gadisa, O. Inganäs and J. V. Manca, Phys. Rev. B: Condens. Matter Mater. Phys., 2010, 81, 125204.

25 K. Vandewal, K. Tvingstedt, A. Gadisa, O. Inganas and J. V. Manca, Nat. Mater., 2009, 8, 904.

26 Z. Tang, L. M. Andersson, Z. George, K. Vandewal, K. Tvingstedt, P. Heriksson, R. Kroon, M. R. Andersson and O. Inganas, Adv. Mater., 2012, 24, 554.

27 J. C. Blakesley, H. S. Clubb and N. C. Greenham, Phys. Rev. B: Condens. Matter Mater. Phys., 2010, 81, 045210.

28 F. Gao, S. Himmelberger, M. Andersson, D. Hanifi, Y. Xia, S. Zhang, J. Wang, J. Hou, A. Salleo and O. Inganas, Adv. Mater., 2015, 27, 3868.

29 W. F. Pasveer, J. Cottaar, C. Tanase, R. Coehoorn, P. A. Bobbert, P. W. Blom, D. M. de Leeuw and M. A. Michels, Phys. Rev. Lett., 2005, 94, 206601.
30 J. J. Yin, F. Lao, P. P. Fu, W. G. Wamer, Y. Zhao, P. C. Wang, Y. Qiu, B. Sun, G. Xing, J. Dong, X. J. Liang and C. Chen, Biomaterials, 2009, 30, 611.

31 E. B. Zeynalov, N. S. Allen and N. I. Salmanova, Polym. Degrad. Stab., 2009, 94, 1183.

32 J. Schafferhans, A. Baumann, A. Wagenpfahl, C. Deibel and V. Dyakonov, Org. Electron., 2010, 11, 1693.

33 C.-K. Lu and H.-F. Meng, Phys. Rev. B: Condens. Matter Mater. Phys., 2007, 75, 235206.

34 R. Hansson, C. Lindqvist, L. K. Ericsson, A. Opitz, E. Wang and E. Moons, Phys. Chem. Chem. Phys., 2016, 18, 11132.

35 Y. Cai, L. Huo and Y. Sun, Adv. Mater., 2017, 29, 1605437.

36 H. Fu, Z. Wang and Y. Sun, Sol. RRL, 2018, 2, 1700158.

37 P. Cheng, G. Li, X. Zhan and Y. Yang, Nat. Photonics, 2018, $12,131$.

38 J. Hou, O. Inganas, R. H. Friend and F. Gao, Nat. Mater., 2018, 17, 119. 